\title{
Ocorrência de anticorpos de Neospora caninum em vacas leiteiras avaliados pelos métodos ELISA e RIFI no município de Avaré, SP
}

\section{Ocorrence of Neospora caninum antibody in dairy cows assayed by ELISA and IFAT from Avaré county, SP}

\author{
Izidoro Francisco Sartor ${ }^{1 *}$; Marcia Yumiko Hasegawa²; \\ Aurea Maria Oliveira Canavessi ${ }^{3}$; Rhonda Denise Pinckney ${ }^{4}$
}

\begin{abstract}
Resumo
Soros de 521 vacas do município de Avaré, SP, foram analisados pelos métodos de reação de imunofluorescência indireta (RIFI) e teste imunoenzimático (ELISA) para a detecção de anticorpos contra Neospora caninum. As amostras reagentes para Neospora também foram submetidas à RIFI para Toxoplasma gondii. Pelo método de RIFI 15,9\% das amostras foram positivas para $N$. caninum nas diluições de 1:200 a 1:1600 e pelo teste de ELISA 30,5\% dos soros foram positivos. Das amostras positivas para ELISA e negativas para a RIFI 1:200, 46 foram reagentes na diluição de 1:160. Todas as 129 vacas positivas para RIFI nas diluições $\geq 1: 160$ também o foram para ELISA. Dos 44 abortamentos constatados, $14(31,8 \%)$ e $18(40,9 \%)$ vacas apresentaram título na RIFI $\geq 1: 200$ e $\geq 1: 160$, respectivamente, e $24(54,5 \%)$ reagiram ao teste de ELISA. Dos 159 soros que reagiram para $N$. caninum nos testes de RIFI e/ou ELISA, apenas seis foram positivos para $T$. gondii pelo método de RIFI e, das 44 vacas com histórico de abortamentos, apenas uma apresentou anticorpos anti-Toxoplasma. Esses resultados sugerem a presença de $N$. caninum nos rebanhos estudados e sua relação com os abortamentos observados.

Palavras-chave: Neosporose, bovinos, Apicomplexa.
\end{abstract}

\begin{abstract}
Sera of 521 dairy cows from herds in Avaré County, SP were examined by indirect fluorescent-antibody test (IFAT) and enzyme-linked immunosorbent assay (ELISA) for detection of antibodies to Neospora caninum. The positive samples for Neospora were also tested for Toxoplasma gondii by IFAT. By using IFAT $15.9 \%$ of the samples reacted for $N$. caninum with dilution between 1:200 and 1: 1600. By using ELISA $30.5 \%$ were seropositive for Neospora. Of the samples that were positive to ELISA and negative to IFAT for antibodies titers of 1:200, 46 showed IFAT titers of 1:160. All 129 cows that were seropositive to IFAT with titers of 1:200 and 1:160 were also positive to ELISA. Out of 44 detected abortions, 14 $(31.8 \%)$ and $18(40.9 \%)$ cows had IFAT titers of $\geq 1: 200$ and $\geq 1: 160$, respectively, and $24(54.5 \%)$ cows were positive to ELISA. Of the 159 seropositive samples to $N$. caninum to IFAT and/or ELISA, only six were positive to IFAT to $T$. gondii. Moreover, among the 44 cows with history of abortion, only one demonstrated antibodies to Toxoplasma. These results suggest the presence of $N$. caninum in the herds that were evaluated and the potential relationship with the observed abortions.
\end{abstract}

Key words: Neosporosis, bovine, Apicomplexa.

\footnotetext{
${ }^{1}$ Professor .Dr. Universidade Estadual Paulista/ Universidade do Oeste Paulista, Pró-Reitoria de Pesquisa e Pós-Graduação. Email: sartor@.posgrad.unoeste.br

${ }^{2}$ Aluna de Doutorado no Departamento de Clínica Médica/FMVZ, da Universidade de São Paulo. (USP).

${ }^{3}$ Aluna de Ph.D., Department of Animal Health and Biomedical Sciences, SVM, University of Wisconsin - Madison, USA.

${ }^{4}$ Assistant Professor, Department of Pathobiological Sciences, SVM, University of Wisconsin - Madison, USA.

* Autor para correspondência.
} 
Sartor, I. F. et al.

\section{Introdução}

Estudando cães portadores de miosite e encefalite Bjerkas, Mohn e Presthus (1984), chamaram a atenção para um parasita com estrutura semelhante ao Toxoplasma gondii. Dubey et al. (1988) isolaram e classificaram tal parasita denominando-o Neospora caninum. O hospedeiro definitivo, o cão, foi descoberto mais tarde por Mcallister et al. (1998). Parasita do filo Apicomplexa, família Sarcocystidae é o agente causador da neosporose. Atualmente essa doença é tida como a maior causa de abortamento bovino em muitos países (DUBEY, 1999). O custo de abortamentos induzidos por $N$. caninum na Califórnia, relacionado à atividade leiteira é estimado em 35 milhões de dólares anuais (ANDERSON et al., 1991). Locatelli-Dittrich et al. (2001) constataram que o risco de abortamento em vacas ELISAsoropositivas para $N$. caninum é de 3,3 a 4 vezes maior do que em vacas ELISA-soronegativas. $A$ detecção de anticorpos específicos é rotineiramente utilizada como indicativo da infecção, sendo a reação de imunofluorêscencia indireta (RIFI) amplamente utilizada (PARÉ; HIETALA; THURMOND, 1995a). As taxas de animais positivos nos rebanhos variam muito, e essa variação está na dependência do método de diagnóstico utilizado, da procedência da amostra, isto é, se a mesma é proveniente de rebanhos com abortamento endêmico ou é uma amostra aleatória. Taxas de 5\% (HUONG et al., 1998) a $67,3 \%$ (LOCATELLI-DITTRICH et al., 2000).

Paré et al. (1995b), desenvolveram o teste de ELISA indireto com taquizoítas rompidos, contudo sua especificidade tem sido questionada (DUBEY et al., 1996b). Este teste, pela sua praticidade, pode ser utilizado para auxiliar o profissional em aquisições de animais ou para levantamentos sorológicos em rebanhos, condutas que se constituem um grande passo para o desenvolvimento de um plano estratégico para o controle dessa doença (THURMOND; HIETALA, 1995; THURMOND; HIETALA; BLANCHARD, 1997).

No Brasil, Gondim et al. (1999), detectaram, pelo método de imunoistoquímica, o $N$. caninum em um feto abortado de 8 meses, cujo título de anticorpos no soro foi de 1:6400. Nessa propriedade, com histórico de abortamentos, do soro de dez vacas submetidos à RIFI, seis foram positivos com títulos de 1:800 (três), 1:1600 (dois), 1:3200 (um), sendo que a literatura considera como específicos, títulos iguais ou superiores a 200 (REICHEL; DRAKE, 1996). Corbellini et al. (2002), realizaram um estudo histopatológico em 46 fetos bovinos abortados no Estado do Rio Grande do Sul, Brasil. Dezoito de 22 $(81,8 \%)$ fetos com quadro de encefalite apresentaram reação sorológica com antisoro de $N$. caninum.

O objetivo do ensaio foi a determinação da ocorrência de anticorpos anti- $N$. caninum, em rebanhos leiteiros do município de Avaré, SP, avaliando dois métodos sorológicos, ELISA e RIFI, e suas relações com os abortamentos. A ocorrência de anticorpos anti- $T$. gondii também foi avaliada através da RIFI em animais onde foram detectados anticorpos contra N. caninum.

\section{Material e Métodos}

Soros de 521 vacas, em sua maioria da raça Holandês malhada de preto, gestantes ou que estiveram nessa situação fisiológica em pelo menos uma vez, pertencentes a dez propriedades do município de Avaré, SP, foram submetidos aos métodos de RIFI e ELISA*.

Das propriedades estudadas, oito possuíam manejo profilático adequado de seus rebanhos. Todas vacinavam seus animais contra o complexo IBR/ BVD, Leptospirose e Brucelose. Como é utilizada a inseminação artificial nessas propriedades, doenças venéreas abortivas também são praticamente descartadas.

Para a RIFI, foram consideradas positivas diluições iguais ou superiores a 1:200. Diluições de 1:160 foram realizadas quando o ELISA era positivo e a RIFI 1:200 negativa. Para ELISA, os resultados

\footnotetext{
* Neospora caninum Antibody Test Kit - e-mail: Sayd @ Idexx.com
} 
foram estabelecidos conforme software do fabricante do "kit".

As lâminas sensibilizadas com taquizoítos de Neospora caninum foram preparadas na Escola de Medicina Veterinária da Universidade de Wisconsin, Madison, E.U.A.. Um conjugado de anticorpos secundários anti-bovino IgG (bovino IgG1,2; VMRD, Pullman, Washington) foi utilizado na técnica. O título foi determinado como aquela diluição do soro em que se evidenciou fluorescência em toda a periferia dos taquizoítos (DUBEY; LINDSAY, 1996a). As amostras que não apresentavam fluorescência periférica total no parasita, ou que mostravam fluorescência apenas em sua extremidade, conhecida como fluorescência polar, foram consideradas negativas.

Os soros positivos para $N$. caninum, na RIFI ou ELISA, foram submetidos também à RIFI para Toxoplasma gondii, segundo o método descrito por Camargo (1974), sendo consideradas positivas diluições iguais ou superiores a 1:16. Para a interpretação dos resultados da RIFI também foi utililzado o processo descrito anteriormente para $N$. caninum.

$\mathrm{Na}$ análise estatística foi utilizado o teste de McNemar (SIEGEL, 1975) para verificar se existia concordância entre os métodos de ELISA e RIFI quanto à característica de interesse.

\section{Resultados e Discussão}

Na RIFI, $15.9 \%$ das amostras foram positivas para diluições que variaram de 1:200 a 1:1600; para ELISA, $30,5 \%$ dos soros resultaram em positividade; comparando-se a RIFI 1:200 e/ou 1:160 com o ELISA, constatou-se que todos os animais positivos para RIFI também o foram para ELISA e, daqueles positivos para ELISA e negativos para RIFI 1:200, 46 amostras foram reagentes quando a diluição da RIFI foi de 1:160; analisando-se abortamento versus RIFI 1:200 e/ou 1:160, do total de 44 abortamentos constatados, $14(31,8 \%)$ estavam inclusos na faixa de diluição de 1:200 ou superior e, mais quatro soros na de 1:160, perfazendo um total de $18(40,9 \%)$ casos; avaliando-se abortamento versus ELISA, 24 (54,5\%) dos animais que abortaram foram reagentes a esse método; dos soros reagentes para a RIFI ou ELISA, submetidos à RIFI para $T$. gondii, apenas seis amostras foram positivas.

Embora a detecção de anticorpos em um indivíduo seja uma evidência insuficiente para se afirmar ser aquele único agente responsável por uma doença num rebanho sua presença, particularmente quando específicos, é de grande utilidade para o estudo epidemiológico de qualquer enfermidade.

Os métodos mais utilizados em estudos epidemiológicos são a RIFI e o teste ELISA. Para a RIFI, embora haja alguma divergência entre os autores sobre qual seria o ponto de corte para triagem em bovinos adultos, uma diluição de 1:200 parece ser a mais aceita (DUBEY; LINDSAY, 1993). Um estudo realizado por Conrad et al. (1993), demonstrou que $87 \%$ de animais sem histórico de neosporose apresentaram títulos inferiores a 160. Logo, neste ensaio, animais com títulos iguais ou superiores a 200 foram considerados positivos. Títulos muito altos podem ser detectados em determinados momentos da infecção. Na interpretação dos resultados, deve ser levado em consideração o espaço de tempo decorrido entre o abortamento e a colheita do sangue. Este fato é justificado pela queda de persistência nos títulos da RIFI após o abortamento. Vacas com títulos de RIFI $\geq 640$, com fetos infectados com $N$. caninum, dentro de 5 meses tiveram um declínio em suas titulações para 160 (CONRAD et al., 1993). O título elevou-se, em um destes animais de 160 para 1280 no parto seguinte, cujo bezerro foi infectado por via congênita. Se houve reativação ou reinfecção não foi possível a constatação pelos autores.

Patitucci (1994), na Nova Zelândia, relaciona diluições de RIFI de 1:400 como ponto de corte significativo na associação entre $N$. caninum e abortamento. No entanto, Paré, Hietela e Thurmond (1995a), em seus estudos na Califórnia, determinaram que esse título seria de 640 e Trees et al. (1994), que diluições de 1:1280 seriam indicativas de que o $N$. caninum seria uma real causa de abortamentos. 
Para o teste de ELISA, Paré, Hietela e Thurmond (1995b), utilizando lisado de taquizoítos de $N$. caninum como antígeno e um ponto de corte densidade ótica de 0,45 encontraram uma boa correlação de positivos com soros de vacas também positivos para a RIFI, em diluições de 1:1280. Comentam os autores ser o ELISA mais sensível e específico que a RIFI. Um fator favorável observado neste experimento quanto ao ELISA consistiu em sua automação. Isto praticamente eliminou a interferência técnica, a qual é responsável por erros como, por exemplo, os de leitura de uma lâmina. Dentre os vários tipos de ELISA utilizados para detectar anticorpos anti- $N$. caninum encontram-se: ELISA com antígeno recombinante, ELISA cinético, Iscom ELISA, ELISA antígeno de captura por inibição competitiva e ELISA com lisado total de taquizoítos (DUBEY et al., 1997). Este último foi utilizado na pesquisa pela sua disponibilidade e facilidade de execução.

A RIFI anti-T. gondii, foi realizada em animais $N$. caninum positivos para os métodos de RIFI e/ou ELISA. Mesmo não sendo o T. gondii considerado um causador de abortamentos em bovinos (DUBEY; BEATTIE, 1998), esse procedimento foi adotado para avaliar a presença do protozoário no rebanho e sua associação com os abortamentos.

Reações cruzadas entre $N$. caninum e $T$. gondii são pouco possíveis, conforme constatação de Trees et al. (1994 ) e de Dubey et al. (1996b) que, trabalhando com os testes de RIFI e ELISA, em vacas naturalmente ou experimentalmente infectadas, não encontraram reações cruzadas entre esses dois protozoários. Também foi verificado que soro de bezerros infectados com Cryptosporidium parvum e Eimeria bovis não reagiram com $N$. caninum. Trees et al. (1994), também não encontraram reações cruzadas em bovinos infectados com Sarcocystis cruzi, B. divergens, E. bovis, E. albamensis e $C$. parvum. No entanto, reações cruzadas ocorreram entre $S$. cruzi e $N$. caninum quando foi utilizado o método de ELISA (DUBEY et al., 1996b). Este é um fato muito importante, particularmente levandose em consideração a alta prevalência de $S$. cruzi em rebanhos bovinos. Nos EUA, aproximadamente $100 \%$ dos bovinos são expostos à Sarcocystis spp. (DUBEY; LINDSAY, 1996a).

Quanto à idade dos fetos acometidos, especulase que a infecção pode ocorrer no primeiro ou segundo mês de gestação. Nesta situação, esses organismos são reabsorvidos e a vaca retorna ao cio. Tanto nesta situação como em abortamentos precoces, pode haver uma ou mais repetições de cios (OBENDORF et al., 1995; ANDERSON et al., 1995) porém, o período mais freqüente em abortamentos por neosporose, situa-se ao redor dos 2/3 da gestação. Na Califórnia, essa média foi de 5,5 meses (ANDERSON et al., 1991). Em outra pesquisa com 113 abortamentos, tendo como agente também o $N$. caninum, 98 ocorreram na faixa de 4-7 meses de gestação (ANDERSON et al., 1995).

A soroprevalência poderia ser discutida levandose em consideração dois aspectos: a) pela utilização da RIFI ou ELISA em levantamentos epidemiológicos onde as propriedades são escolhidas ao acaso, como neste ensaio; b) pela RIFI ou ELISA, onde o inquérito epidemiológico utiliza animais com histórico de abortamentos. No primeiro aspecto, quando é utilizada a RIFI como método, os resultados assemelham-se aos de Gondim (1999) e ligeiramente superiores aos de Corbellini et al. (2002). No entando, quando essas amostras são submetidas ao ELISA, encontra-se uma porcentagem semelhante à encontrada por Björkman et al. (1996), inferior à descrita por Locatelli-Dittrich et al. (2001), e superior à achada por Huong et al. (1998) e Gottstein et al. (1998).

Na segunda situação, onde é considerado o significativo número de abortamentos, quando utilizase a RIFI, a porcentagem encontrada é inferior às citadas por Reichel e Drake (1996) e Cox, Reichel e Griffiths (1998), porém superior às de Corbellini et al. (2002).

$\mathrm{Na}$ relação entre abortamento e RIFI, considerando-se diluições mínimas de 1:200, e 
abortamento versus ELISA, as porcentagens equivalem às citadas por Thorton, Thompson e Dubey (1991) e Thorton (1992) na Nova Zelândia, e por Onoda e Shirakawa (1997) e Okuda, Fukutomi e Yoshino (1997) no Japão. No entanto, LocatelliDittrich et al. (2001), descrevem porcentagens superiores para associação de animais ELISAsoropositivos com abortamento.

Os dados apresentados nas Tabelas 1 e 2, referemse a comparação dos dois métodos, ELISA e RIFI, em diferentes diluições, na detecção de anticorpos. Na Tabela 1, todas as RIFI positivas também foram ELISA positivos e a situação oposta não ocorreu. Dos 521 soros analisados, 159 amostras detectaram anticorpos anti-Neospora pelo método de ELISA, enquanto que somente 83 acusaram anticorpos na RIFI para diluição 1:200. A análise estatística mostrou ser significativa donde se conclui que os testes RIFI e ELISA não são concordantes, sendo o teste ELISA mais sensível na detecção de anticorpos.

Tabela 1. Teste de McNemar aplicado às amostras de soro de bovinos após serem submetidos aos métodos de RIFI 1:200 e ELISA

\begin{tabular}{|c|c|c|c|}
\hline \multirow[b]{2}{*}{ RIFI 1:200 } & \multicolumn{2}{|c|}{ ELISA } & \multirow[b]{2}{*}{ Tota } \\
\hline & Positivo & Negativo & \\
\hline Positiva & 83 & 0 & 83 \\
\hline Negativa & 76 & 362 & 438 \\
\hline Total & 159 & 362 & 521 \\
\hline
\end{tabular}

$\mathrm{X}^{2}=74,00 ; \mathrm{p}<0,01$.
Tabela 2. Teste de McNemar aplicado às amostras de soros de bovinos, avaliando abortamentos aos métodos RIFI 1:200 e/ou 1:160 e ELISA.

\begin{tabular}{cccc}
\hline & \multicolumn{3}{c}{ Abortamentos } \\
\cline { 3 - 4 } & Positivo & Negativo & Total \\
\cline { 3 - 4 } RIFI 1:200/1:160 & & & 18 \\
\hline Positiva & & 0 & 26 \\
Negativa & 6 & 20 & 44 \\
\hline Total & 24 & 20 & 26 \\
\hline
\end{tabular}

$\mathrm{X}^{2}=4,17 ; \mathrm{p}=0,041$

Das 76 amostras que apresentaram ELISA positivos e RIFI negativas na diluição 1:200, e foram submetidas à RIFI em diluições 1:160, em 46 foram encontrados anticorpos anti-Neospora. A análise estatística demostrou que os métodos RIFI 1:160 e ELISA não são concordantes $\left(X^{2}=28,00 ; p<0,01\right)$, sendo este último mais sensível na constatação destes anticorpos. Trinta das 76 amostras mostraram-se negativas para RIFI de 1:160 porém, positivas para ELISA. Este fato leva ao questionamento, se o método de ELISA estaria também evidenciando falso positivos, por meio de reações cruzadas com outros agentes, conforme citado por Dubey et al. (1996b).

Dos 44 abortamentos, em 14 vacas as titulações pela RIFI, foram iguais ou superiores a 200, com um adicional de quatro animais com titulação de 160 . Para ELISA, desse total de abortamentos, 24 animais acusaram anticorpos anti-Neospora (Tabela 2). Estatisticamente, também não foi observada concordância entre os métodos. O teste ELISA mostrou maior sensibilidade na detecção de anticorpos em abortamentos, concordando muito mais com essa patologia que a RIFI, 24 casos contra 18, mesmo considerando-se na RIFI diluições baixas como 1:160. 
Essa comparação poderia ser maior para ambas as técnicas pois, duas propriedades omitiram o número de abortamentos que, provavelmente, ocorreram. A queda da titulação para 160 de quatro vacas que abortaram pode ser explicada pelo tempo que provavelmente decorreu entre o momento do abortamento e a data da colheita das amostras.

Apenas seis $(3,8 \%)$ das 159 amostras com anticorpos anti-Neospora, foram positivas para $T$. gondii em diluições $\geq 1: 16$. Como esses testes não foram realizados em toda a amostragem e sim nos positivos para neosporose e devido à improvável reação cruzada com $T$. gondii, sugere-se que a presença desses anticorpos, provavelmente, se deva à infecção dos animais por esse parasita. Em apenas um abortamento, houve o encontro de anticorpos para ambos os protozoários. Esse fato corrobora Dubey e Beattie (1998) à respeito da pouca importância desse protozoário, T. gondii, nas patologias de abortamento em bovinos, e sua baixa freqüência nessa espécie animal.

\section{Conclusões}

1- A ocorrência de anticorpos contra N. caninum em rebanhos leiteiros, do município de Avaré-SP, foi de $15,9 \%$ quando foi utilizado o método de RIFI e de $30,5 \%$ quando as amostras foram submetidas ao método de ELISA.

2- O método de ELISA mostra-se prático e rápido, detectando um número superior de animais com anticorpos anti-Neospora que a RIFI porém, para a avaliação de sua especificidade, outros testes são requeridos.

3- O método da RIFI detecta um número superior de animais com anticorpos anti-Neospora quando são utilizadas diluições de 1:160 mas, ainda assim, o número de animais é inferior ao detectado pelo método de ELISA.

4- Na detecção de anticorpos contra Neospora o método de ELISA mostra maior concordância com abortamentos do que a RIFI, mesmo quando realizada em diluições de 1:160.
5- A pequena porcentagem de animais positivos para $T$. gondii, dentre os animais que abortaram, e sua presença em amostragem dos rebanhos da região mostram a pouca importância desse parasita para bovinos.

6- Levando-se em consideração o grande número de animais soropositivos para $N$. caninum que abortaram e o rígido esquema profilático adotado por algumas propriedades, há fortes indícios que a presença deste protozoário seja a principal causa dos abortamentos registrados.

\section{Agradecimentos}

À FAPESP pelo financiamento total do projeto, fornecendo todo material permanente e de consumo (Processo FAPESP: 1997/14436-0).

\section{Referências}

ANDERSON, M. L.; BLANCHARD, P. C.; BARR, B.C.; DUBEY, J. P.; HOFFMAN, R. L.; CONRAD, P. A. Neospora-like protozoan infection as a major cause of abortion in California dairy cattle. Journal of the American Veterinary Medical Association, Schaumburg, v.198, p.241-244, 1991.

ANDERSON, M. L.; PALMER, C. W.; THURMOND, M. C.; PICANSO, J. P.; BLANCHARD, P. C.; BREITMEYER, R. E.; LAYTON, A. W.; McALLISTER, M.; DAFT, B.; KINDE, H.; READ, D. H.; DUBEY, J. P.; CONRAD, P. A.; BARR, B. C. Evaluation of abortions in cattle atributable to neosporosis in selected dairy herds in California. Journal of the American Veterinary Medical Association, Schaumburg, v.207, p.1206-1210, 1995.

BJERKAS, I.; MOHN, S. F.; PRESTHUS, J. Unidentified cyst-forming sporozoan causing encephalomyelitis and myositis in dogs. Zeitschrift fur Parasitenkunde, Jena, v.70, p.271-274, 1984.

BJÖRKMAN, C.; JOHANSSON, O.; STENLUND, S.; HOLMDHAHL, J.; UGGLA, A. Neospora species infection in a herd of dairy cattle. Journal of the American Veterinary Medical Association, Schaumburg, v.188, p.1441-1444, 1996.

CAMARGO, M. E. Introdução às técnicas de imunofluorescência. Revista Brasileira de Patolologia Clínica, v.10, p.143-169, 1974. 
CONRAD, P. A.; SVERLOW, K.; ANDERSON, M.; ROWE, J.; BONDURANT, R.; TUTER, G.; BREITMEYER, R.; PALMER, C.; THURMOND, M.; ADAMS, A.; DUBEY, J.P.; DUHAMEL, G.; BARR, B. Detection of serum antibody responses in cattle with natural or experimental Neospora infections. Journal of Veterinary Diagnostic Investigation, Columbia, v.5, p.572-578, 1993.

CORBELLINI, L. G.; DRIEMEIER, D.; CRUZ, C. F.; GONDIM, L. F.; WALD, V. Neosporosis as a cause of abortion in dairy cattle in Rio Grande do Sul, southern Brazil. Veterinary Parasitology, Amsterdam, v.103, n.3, p.195-202, jan. 2002.

COX, B. T.; REICHEL, M. P.; GRIFFITHS, L. M. Serology of a Neospora abortion outbreak on a dairy farm in New Zealand: a case study. New Zealand Veterinary Journal, Wellington, v.46, p.28-31, 1998.

DUBEY, J. P. Recent advances in Neospora and neosporosis. Veterinary Parasitology, Amsterdam, v.84, p.349-367, 1999.

DUBEY, J. P.; BEATTIE, C. P. Toxoplamosis of Animals and Man. Boca Raton: CRC Press, 1998.

DUBEY, J. P.; CARPENTER, J. L.; SPEER, C. A.; TOPPERRK, M. J.; UGGLA, A. Newly recognized fatal protozoan disease of dogs. Journal of the American Veterinary Medical Association, Schaumburg, v.192, p.1269-1285, 1988.

DUBEY, J. P.; JENKINS, M. C.; ADAMS, D. S.; McALLISTER, M. M.; ANDERSON, M. L.; SPRECHER, R.; BASZIER, T. V.; KWOK, O. C. H.; LALLY, N. C.; BJÓRKMAN, C.; UGGIA, A. Antibody responses of cows during na outbreak of neosporosis evaluated by indirect fluorescent antibody test and different enzyme-linked immunosorbent assays. Journal of Parasitology, Amsterdam, v.83, p.1063-1069, 1997.

DUBEY, J. P.; LINDSAY, D. S. A review of Neospora caninum and neosporosis. Veterinary Parasitology, Amsterdam, v.67, p.1-59, 1996a.

DUBEY, J. P.; LINDSAY, D. S. Neosporosis. Parasitology Today, Amsterdam, v.9, p.452-458, 1993.

DUBEY, J. P.; LINDSAY, D. S.; ADAMS, D. S.; GAY, J. M.; BASZLER, T. V.; BLAGBURN, B. L.; THULLIEZ, P. Serologic responses of cattle and other animals infected with Neospora caninum. American Journal of Veterinary Research, Chicago, v.57, p.329-336, 1996b.

GONDIM, L. F. P. Prevalência de anticorpos contra Neospora caninum em vacas leiteiras na microrregião de Feira de Santana, Bahia, e detecção do parasita em um feto abortado no Brasil. 1999. Dissertação (Mestrado) - Universidade Estadual Paulista Júlio de Mesquita Filho, Botucatu - SP.
GONDIM, L. F. P.; SARTOR, I. F.; MONTEIRO JR., L. A.; HARITANI, M. Neospora caninum infection in an aborted bovine fetus in Brazil. New Zealand Veterinary Journal, Wellington, v. 47, p.35, 1999.

GOTTSTEIN, B.; HENTRICH, B.; WYSS, R.; THUR, B.; BUSATO, A.; STÄRK, K. D. C.; MÜLLER, N. Molecular and immunodiagnostic investigations on bovine neosporosis in Switzerland. International Journal for Parasitology, Elmsford, v.28, p.679-691, 1998.

HUONG, L. T. T.; LJUNGSTROM, B. L.; UGGLA, A.; BJÖRKMAN, C. Prevalence of antibodies to Neospora caninum and Toxoplasma gondii in cattle and water buffaloes in Southern Vietnam. Veterinary Parasitology, Amsterdam, v.75, p.53-57, 1998.

LOCATELLI-DITTRICH, R.; SOCCOL, V. T.; RICHARTZ, R. R.; GASINO-JOINEAU, M. E.; VINNE, R.; PINCKNEY, R. D. Serological diagnosis of neosporosis in a herd of dairy cattle in southern Brazil. Journal of Parasitology, Lawrence, v.87, n.6, p.1493-1494, dec. 2001.

MCALLISTER, M. M.; DUBEY, J.P.;LINDSAY,D. S.; JOLLEY, W. R.; WILLIS, R. A.; McGUIRE, J. A. Dogs are defenitive hosts of Neospora caninum. International Journal for Parasitology, Elmsford,v.28, p.1473-1478, 1998.

OBENDORF, D. L.; MURRAY, N.; VELDHUIS, G.; MUNDAY, B. L.; DUBEY, J. P. Abortion caused by neosporosis in cattle. Australian Veterinary Journal, Brunswick, v.72, p.117-118, 1995.

OKUDA, K.; FUKUTOMI, T.; YOSHINO, T. Detection of Neospora antibody and antigens from bovine cases of abortions in Okayama Prefecture. Journal of Japanese Veterinary Medical Association, Tokio, v.50, p.386-389, 1997.

ONODA, Y.; SHIRAKAWA, H. Survey of antibody to Neospora in aborted dairy cows. Journal of Japanese Veterinary Medical Association, Tokyo, v.50, p.258-261, 1997.

PARÉ, J.; HIETALA, S. K.; THURMOND, M. C. An enzyme-linked immunosorbent assay (ELISA) for serological diagnosis of Neospora sp. infection in cattle. Journal of Veterinary Diagnostic Investigation, Columbia, v.7, p.352-359, 1995 b.

PARÉ, J.; HIETALA, S. K.; THURMOND, M. C. Interpretation of an indirect fluorescent antibody test for diagnosis of Neosopora sp. infection in cattle. Journal of Veterinary Diagnostic Investigation, Columbia, v.7, p.273-275, 1995a.

PATITUCCI, A. N. Neospora and abortion in New Zealand dairy cattle. Palmerston North: Massey University, 1994.

REICHEL, M. P.; DRAKE, J. M. The diagnosis of Neospora abortions in cattle. New Zealand Veterinary Journal, Wellington, v.44, p.51-54, 1996. 
SIEGEL, S. Nonparametric Statistics for the Behavioral Sciences. New York: McGraw-Hill, 1975.

THORTON, R. N. Bovine abortions - laboratory diagnosis. Surveillance, Wellington, v.19, p.24, 1992.

THORTON, R. N.; THOMPSON, E. J.; DUBEY, J. P. Neospora abortion in New Zealand cattle. New Zealand Veterinary Journal, Wellington, v.39, p.129-133, 1991.

THURMOND, M. C.; HIETALA, S. K. Strategies to control Neospora infection in cattle. Bovine Practitioner, Stillwater, v.29, p.60-63, 1995.
THURMOND, M. C.; HIETALA, S. K.; BLANCHARD, P.C. Herd-basead diagnosis of Neospora caninum induced endemic and epidemic abortion in cows and evidence for congenital and postnatal transmission. Journal of Veterinary Diagnostic Investigation, Columbia, v.9, p.44-49, 1997.

TREES, A. J.; GUY,F.; LOW, J. C.; ROBERTS, L.; BUXTON, D.; DUBEY, J. P. Serological evidence implicating Neospora species as a cause of abortions in British cattle. Veterinary Record, London, v.134, p.405-407, 1994. 